\title{
Two forms of RNA editing are required for tRNA maturation in Physarum mitochondria
}

\author{
JONATHA M. GOTT, ${ }^{1}$ BENJAMIN H. SOMERLOT, ${ }^{1,3}$ and MICHAEL W. GRAY ${ }^{2}$ \\ ${ }^{1}$ Center for RNA Molecular Biology, Case Western Reserve University, Cleveland, Ohio 44106, USA \\ ${ }^{2}$ Department of Biochemistry and Molecular Biology, Dalhousie University, Halifax, Nova Scotia B3H 1X5, Canada
}

\begin{abstract}
The mitochondrial genome of Physarum polycephalum encodes five tRNAs, four of which are edited by nucleotide insertion. Two of these tRNAs, RNA $^{\text {met1 }}$ and RRNA $^{\text {met2 }}$, contain predicted mismatches at the beginning (proximal end) of the acceptor stem. In addition, the putative $5^{\prime}$ end of RNA $^{\text {met2 }}$ overlaps the $3^{\prime}$ end of a small, abundant, noncoding RNA, which we term ppoRNA. These anomalies led us to hypothesize that these two Physarum mitochondrial tRNAs undergo additional editing events. Here, we show that tRNA ${ }^{\text {met1 }}$ and RRNA $^{\text {met2 }}$ each has a nonencoded $G$ at its $5^{\prime}$ end. In contrast to the other nucleotides that are added to Physarum mitochondrial RNAs, these extra $G$ residues are likely added post-transcriptionally based on (1) the absence of added $G$ in precursor transcripts containing inserted $C$ and AA residues, (2) the presence of potential intermediates characteristic of $5^{\prime}$ replacement editing, and (3) preferential incorporation of GTP into tRNA molecules under conditions that do not support transcription. This is the first report of both post-transcriptional nucleotide insertions and the addition of single Gs in $P$. polycephalum mitochondrial transcripts. We postulate that tRNA ${ }^{\text {met1 }}$ and tRNA ${ }^{\text {met2 }}$ are acted upon by an activity similar to that present in the mitochondria of certain other amoebozoons and chytrid fungi, suggesting that enzymes that repair the $5^{\prime}$ end of tRNAs may be widespread.
\end{abstract}

Keywords: RNA editing; tRNA; nucleotide substitution

\section{INTRODUCTION}

RNAs in the mitochondria of Physarum polycephalum undergo maturation through an array of RNA editing events, including the insertion of nonencoded nucleotides (Mahendran et al. 1991; Gott et al. 1993; Takano et al. 2001), the deletion of encoded nucleotides (Gott et al. 2005), and C-to-U substitutions (Gott et al. 1993). The vast majority of such changes involve the specific insertion of 1-2 nucleotides (nt) (C, U, AA, UU, GC, CU, GU, or UA) at defined sites. Thus far, nearly 500 insertion sites have been identified, with another approximately 500 insertion sites predicted to occur in mitochondrial RNAs that remain to be characterized (Beargie et al. 2008). Editing creates open reading frames within mRNAs and contributes to the secondary

${ }^{3}$ Present address: Center for Developmental Therapeutics, Seattle Children's Hospital Research Institute, Seattle, WA 98101, USA.

Reprint requests to: Jonatha $M$. Gott, Center for RNA Molecular Biology, Case Western Reserve University, 10900 Euclid Avenue, Cleveland, OH 44106, USA; e-mail: jmg13@case.edu; fax: (216) 368-2010; or Michael W. Gray, Department of Biochemistry and Molecular Biology, Dalhousie University, 5850 College Street, Room 8-F2, Sir Charles Tupper Medical Building, Halifax, Nova Scotia B3H 1X5, Canada; e-mail: m.w. gray@dal.ca; fax: (902) 494-1355.

Article published online ahead of print. Article and publication date are at http://www.rnajournal.org/cgi/doi/10.1261/rna.1958810. and tertiary structures of mitochondrial tRNAs and rRNAs. On average, inserted nucleotides comprise $\sim 4 \%$ of the total residues of mRNAs and $\sim 2 \%$ of the residues of mature rRNAs and tRNAs (Miller et al. 1993; Gott and Rhee 2007).

A variety of tRNA editing events have been reported in mitochondrial tRNAs (Price and Gray 1998), including C-to$\mathrm{U}$ edits in plants (Maréchal-Drouard et al. 1993, 1996a,b; Binder et al. 1994), marsupials (Janke and Pääbo 1993), and trypanosomatid protozoa (Alfonzo et al. 1999); 5' -replacement editing in amoebozoan protists (Lonergan and Gray 1993a,b) and chytridomycete fungi (Laforest et al. 1997); 3' -replacement editing in various metazoan animals (Yokobori and Pääbo 1995a,b, 1997; Tomita et al. 1996) and the jakobid flagellate Seculamonas ecuadoriensis (Leigh and Lang 2004); and insertion editing in slime molds (Antes et al. 1998). First documented in the amoeboid protist Acanthamoeba castellanii (Lonergan and Gray 1993a), 5'-replacement editing of mitochondrial tRNAs has been inferred on the basis of mitochondrial DNA sequence in other amoebozoons such as Dictyostelium discodieum and Polysphondylium pallidum, and edited mitochondrial tRNAs have been characterized in the latter protist (E Schindel and MW Gray, unpubl.). The biochemical characteristics of $5^{\prime}$ tRNA editing in 
A. castellanii (Price and Gray 1999a) and in a phylogenetically unrelated chytrid fungus, Spizellomyces punctatus (Bullerwell and Gray 2005), are strikingly similar, suggesting very similar mechanisms in the two cases. These editing activities may be evolutionarily related to those involved in $5^{\prime}$ end maturation of nuclear histidine tRNAs (Cooley et al. 1982), although the histidine guanylyltransferases add a $G$ at position -1 rather than +1 .

The Physarum mitochondrial genome encodes five tRNA genes, and four of the five tRNA products have been shown to contain extra, nonencoded nucleotides (Antes et al. 1998). Curiously, two of the five tRNAs encoded in the Physarum mitochondrial genome are predicted to contain mismatches at the beginning (proximal end) of the acceptor stem: a UxC in tRNA ${ }^{\text {met1 }}$ and a $\mathrm{CxC}$ in tRNA ${ }^{\text {met2 }}$ (Fig. 1A; Antes et al. 1998). In addition, the predicted tRNA ${ }^{\text {met2 }}$ product appears to overlap by a single nucleotide a small, abundant, noncoding RNA (ppoRNA) (Fig. 1B; C Bullerwell, G Burger, J Gott, O Kourennaia, M Schnare, and M Gray, unpubl.). Based on these observations, we hypothesized that the production of the mature forms of $\mathrm{tRNA}^{\text {met1 }}$ and $\mathrm{tRNA} \mathrm{met}^{\mathrm{met}}$ requires an additional RNA editing event at their $5^{\prime}$ ends that would create standard G-C base-pairs.

Two of the known forms of tRNA editing could operate to generate base-paired acceptor stems in Physarum mitochondrial tRNA ${ }^{\text {met1 }}$ and $\mathrm{tRNA}^{\text {met2 }}$, which are matured from longer, polycistronic transcripts (Antes et al. 1998; Byrne and Gott 2004). In Physarum mitochondria, the insertion of nonencoded nucleotides is a cotranscriptional process in which extra residues are added at specific sites within nascent transcripts (Cheng et al. 2001). It is therefore possible that the predicted editing events occur via cotranscriptional insertion of a $G$ at the $5^{\prime}$ end of each tRNA, followed by endonucleolytic cleavage of the primary transcript, presumably by RNase P. Alternatively, these tRNAs could undergo an additional form of RNA editing similar to the post-transcriptional $5^{\prime}$ replacement editing observed in the mitochondria of A. castellanii (Lonergan and Gray 1993a,b) and S. punctatus (Laforest et al. 1997).

Here, we demonstrate that tRNA ${ }^{\text {met1 }}$ and tRNA ${ }^{\text {met2 }}$ contain, at their $5^{\prime}$ ends, the predicted $G$ residues that would create a standard 5' G:C 3' base-pair at the beginning of the acceptor stem of each tRNA. We also provide strong evidence that these $\mathrm{G}$ residues are added by a post-transcriptional $5^{\prime}$ replacement mechanism rather than the cotranscriptional mechanism responsible for nucleotide additions in internal regions of tRNAs, rRNAs, and mRNAs. Thus, maturation of tRNAs in Physarum mitochondria involves two separate forms of editing involving nonencoded nucleotides: cotranscriptional insertion within internal regions and posttranscriptional changes at $5^{\prime}$ termini. These data add to the already impressive number of distinct editing mechanisms operating in Physarum mitochondria. The implications of these findings are discussed.
A
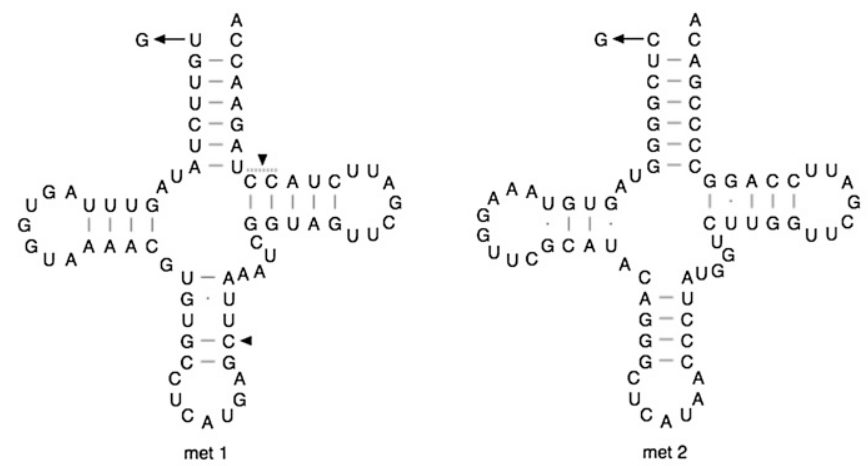

B

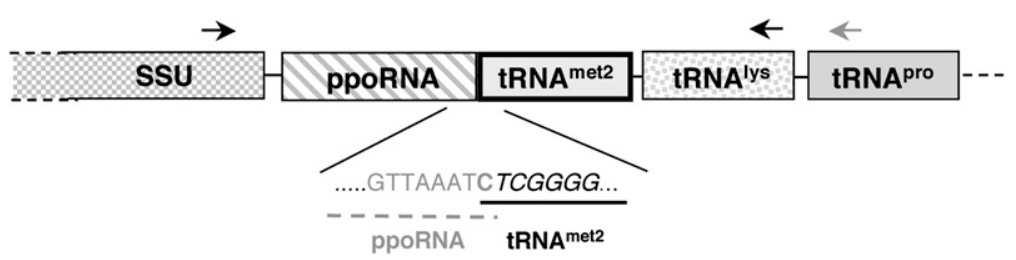

FIGURE 1. 5' RNA editing is predicted for two of the five tRNAs encoded in the mitochondrial genome of Physarum polycephalum. (A) Mitochondrial tRNA ${ }^{\text {met1 }}$ and tRNA ${ }^{\text {met2 }}$ each contain a mismatch at the beginning of the acceptor stem (Antes et al. 1998). Sites predicted to contain a $\mathrm{G}$ residue in the mature tRNA products are indicated with arrows; sites of internal C insertions identified by Antes et al. (1998) are indicated with arrowheads. (B) Apparent overlap of the $5^{\prime}$ end of tRNA ${ }^{\text {met2 }}$ with the $3^{\prime}$ end of ppoRNA. The approximate positions of primers used for reverse transcription (gray) and PCR (black) of nascent transcripts are shown.

\section{RESULTS AND DISCUSSION}

Internal editing sites within the tRNAs encoded in the Physarum mitochondrial genome have been reported previously (Antes et al. 1998). Interestingly, two of the tRNAs, met1 and met2, were each predicted to have a mismatch at the first base pair of the acceptor stem (positions 1:72, standard numbering) (Fig. 1A). Lack of pairing at these positions is a characteristic feature of initiator tRNA ${ }^{\text {met }}$ in prokaryotes and organelles (Jühling et al. 2009); but given the existence of RNA editing in Physarum mitochondria, we suspected that these apparent mismatches might be "corrected" in the mature tRNA products.

The Physarum mitochondrial tRNA ${ }^{\text {met2 }}$ is synthesized as part of a longer transcript that minimally includes the small subunit (SSU) rRNA, ppoRNA, tRNA $^{\text {met2 }}$, tRNA ${ }^{\text {lys }}$, and tRNA ${ }^{\text {pro }}$ (Fig. 1B; Antes et al. 1998; Byrne and Gott 2004). Characterization of the abundant ppoRNA, which is encoded immediately upstream of the tRNA ${ }^{\text {met2 }}$ gene, 
indicated that about $73 \%$ of these molecules have a $\mathrm{C}$ at their $3^{\prime}$ end, with the remaining molecules ending in a $\mathrm{U}$ (C Bullerwell, G Burger, J Gott, O Kourennaia, M Schnare, and $\mathrm{M}$ Gray, unpubl.). Given that there is only a single encoded $\mathrm{C}$ at this position and that it was previously suggested this $\mathrm{C}$ is the $5^{\prime}$ end of tRNA ${ }^{\text {met2 }}$ (Antes et al. 1998), it is possible that an extra residue is added at this position in the primary transcript. We therefore decided to characterize both the mature tRNA species and the nascent transcript.

\section{A $G$ residue is present at the $5^{\prime}$ end of $t R N A^{\text {met1 }}$ and tRNA ${ }^{\text {met2 }}$}

To determine the nucleotide present at the $5^{\prime}$ end of tRNA ${ }^{\text {metl }}$ and tRNA ${ }^{\mathrm{met} 2}$, we used the strategy employed by Price and Gray (1999b) to characterize mature mitochondrial tRNAs in A. castellanii. In this approach, tRNAs are circularized with RNA ligase prior to RT-PCR, cloning, and sequencing (Lohan and Gray 2004, 2007). As a control, using the same strategy, we also examined tRNA ${ }^{\text {pro }}$, which is inferred not to undergo $5^{\prime}$ editing. As we predicted, many tRNA ${ }^{\text {met1 }}$ and tRNA ${ }^{\text {met2 }}$ molecules had a $\mathrm{G}$ rather than the encoded $\mathrm{C}$ (in the case of met2) or $\mathrm{U}$ (met1) at their $5^{\prime}$ ends, with all tRNA ${ }^{\text {met } 1}$ clones also containing the expected internal $\mathrm{C}$ insertion (Fig. 2). Similar experiments using primers specific for circularized tRNA $^{\text {pro }}$ indicated that all tRNA ${ }^{\text {pro }}$ clones contained both of the internally added $\mathrm{C}$ residues (Fig. 2, blue asterisks) but had the encoded $\mathrm{C}$ at their $5^{\prime}$ ends; i.e., no evidence of $5^{\prime}$ editing was seen for this tRNA. All clones derived from circularized tRNA contained a $3^{\prime}$-CCA end, but no inferences can be drawn from this observation due to the possibility of preferential ligation of tRNAs having this structure. From these experiments, we conclude that some form of $5^{\prime}$-replacement editing occurs during the maturation of tRNAs having a mismatch at the beginning of the acceptor stem.

\section{Presence of potential editing intermediates}

Interestingly, none of the cloned RT-PCR products derived from circularized tRNA ${ }^{\text {metl }}$ contained the encoded $5^{\prime} \mathrm{U}$, but more than half were missing the $5^{\prime}$ nucleotide entirely (Fig. $2 A)$. Since tRNA ${ }^{\text {metl }}$ occupies the $5^{\prime}$ end of the tRNA ${ }^{\text {met1 }}$ tRNA $^{\text {glu2 }}$ precursor RNA (Antes et al. 1998), such molecules could potentially be generated via either initiation of transcription at position +2 or cleavage at the position of the mismatched U. As was the case with the completely edited molecules, all of the $5^{\prime}$-truncated tRNA ${ }^{\text {metl }}$ clones contained both the internal $\mathrm{C}$ insertion and a $3^{\prime}$-CCA end (Fig. 2A), suggesting that these tRNAs could potentially be intermediates in a $5^{\prime}$ editing reaction. Circularized tRNA ${ }^{\text {met2 }}$ clones lacking the $5^{\prime}$ nucleotide were not observed, but one contained a $\mathrm{C}$ at its $5^{\prime}$ end (Fig. 2B). This clone must be derived from processed RNA based on the added CCA at the circularization junction, and is likely a result of processing between the ppoRNA and tRNA $^{\text {met2 }}$ (Fig. 1), since about $25 \%$ of ppoRNA molecules
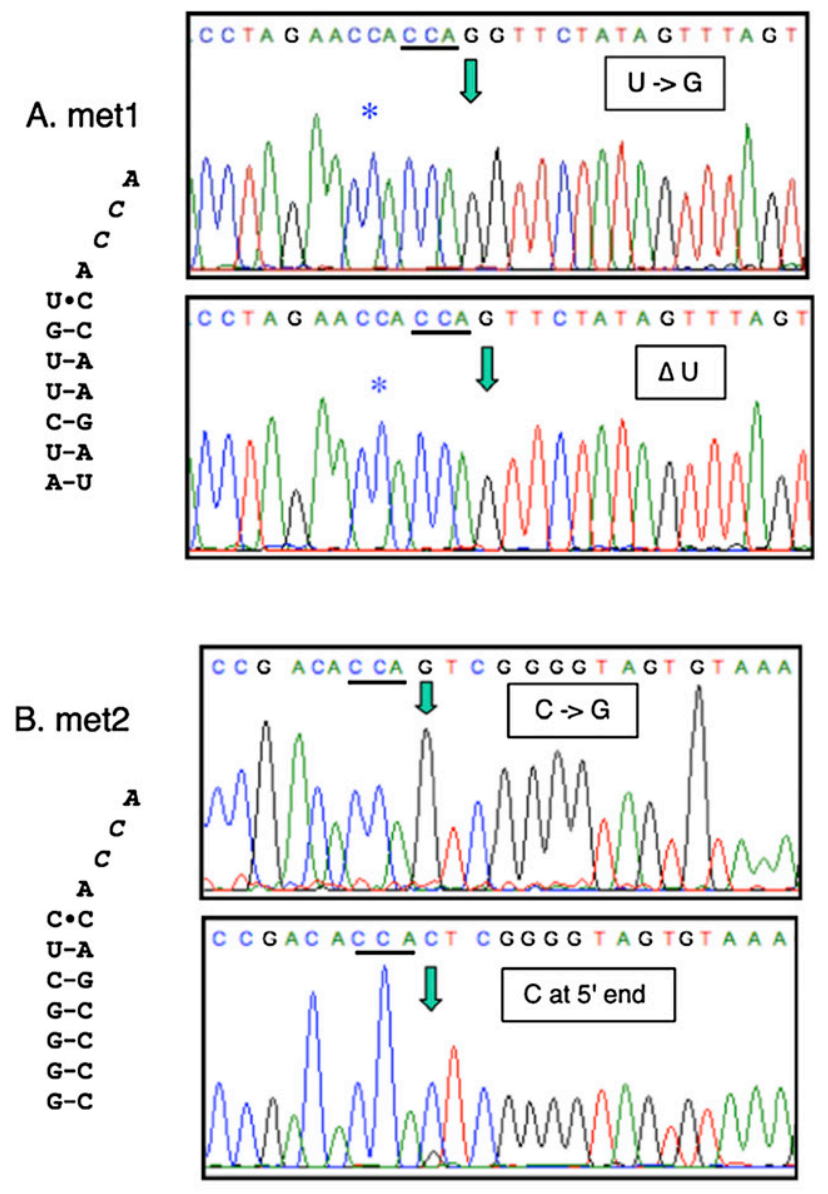

C. pro

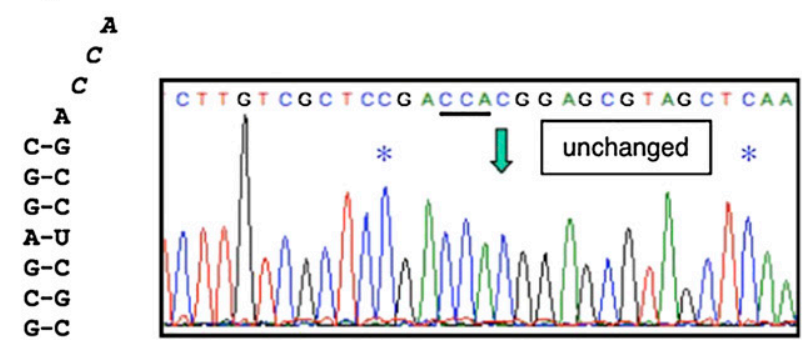

FIGURE 2. Editing at the $5^{\prime}$ ends of $\mathrm{tRNA}^{\text {met1 }}$ and $\mathrm{tRNA}^{\text {met2 }}$ Sequence of representative cloned RT-PCR products derived from circularized tRNAs; traces of the region between the primers used for PCR amplification are shown. The nonencoded CCA ends (italics) are underlined, and the $5^{\prime}$ ends of the mature tRNAs are indicated by green arrows in the traces. Internal $\mathrm{C}$ insertion sites are indicated with blue asterisks. (A) The acceptor stem of tRNA ${ }^{\text {metl }}$ and traces from clones with a $\mathrm{G}$ at its $5^{\prime}$ end (edited, top) or missing the $5^{\prime}$ nucleotide (potential editing intermediate, bottom). Both contain the extra $\mathrm{C}$ that is added in this region. (B) Acceptor stem of tRNA ${ }^{\text {met2 } 2}$ and traces from tRNA ${ }^{\text {met2 }}$ clones having a 5' G (edited, top) or C (unedited, bottom). (C) Clone from circularized tRNA ${ }^{\text {pro }}$ containing the encoded $\mathrm{C}$ at its $5^{\prime}$ end and internal $\mathrm{C}$ insertions.

have a $U$ at their $3^{\prime}$ ends (C Bullerwell, G Burger, J Gott, O Kourennaia, M Schnare, and M Gray, unpubl.). The presence of tRNA ${ }^{\text {met2 }}$ having a $\mathrm{C}$ at its $5^{\prime}$ end is not consistent 
with a mechanism involving cotranscriptional $G$ insertion, although the possibility of partial editing at this site cannot be ruled out. Antes et al. (1998) have reported partial editing of unprocessed tRNA precursors, but in all cases cDNAs derived from processed tRNAs were fully edited.

\section{Absence of added $G$ residue in primary transcripts}

To determine whether a $\mathrm{G}$ is added during transcription of the tRNA ${ }^{\text {met2 }}$ precursor, we generated RT-PCR products derived from the nascent transcript using primers specific for genes lying upstream (SSU rRNA) and downstream $\left(\right.$ tRNA $\left.^{\text {lys }}\right)$ of the tRNA ${ }^{\text {met2 }}$ gene. The same primers were also used to amplify the genomic sequence. Sequence traces from the bulk PCR and RT-PCR products are shown in Figure 3. The precursor RNA clearly does not have an added $\mathrm{G}$ (or any other added nucleotide) at the $5^{\prime}$ end of tRNA $^{\text {met2 }}$, despite the fact that all other nonencoded nucleotides both upstream and downstream are present. This finding is consistent with previous results with cloned RT-PCR products derived from this region. In those experiments, all RT-PCR clones representing nascent (unprocessed) transcripts made in vivo were completely edited by nucleotide insertion at known insertion sites, but none contained an extra $\mathrm{G}$ at the $5^{\prime}$ end of tRNA ${ }^{\text {met2 }}$ (Byrne and Gott 2004). Likewise, none of 16 independent partially edited clones made during run-on transcription in vitro had an inserted $G$ at this position despite high levels of editing at other sites (Byrne and Gott 2004). Thus, we

\section{A. bulk PCR product}

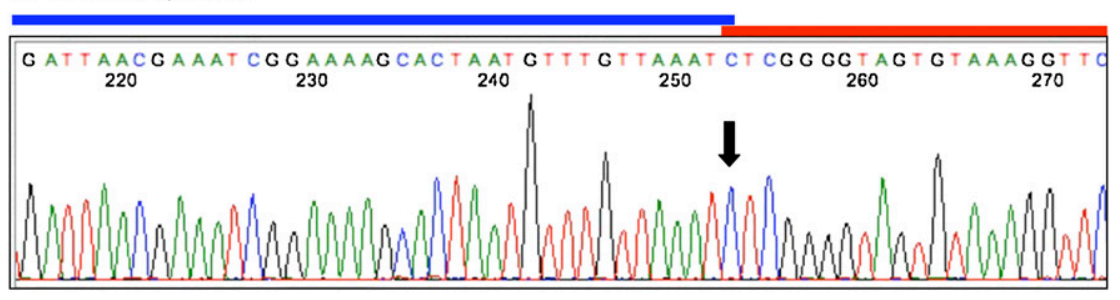

B. bulk RT-PCR product

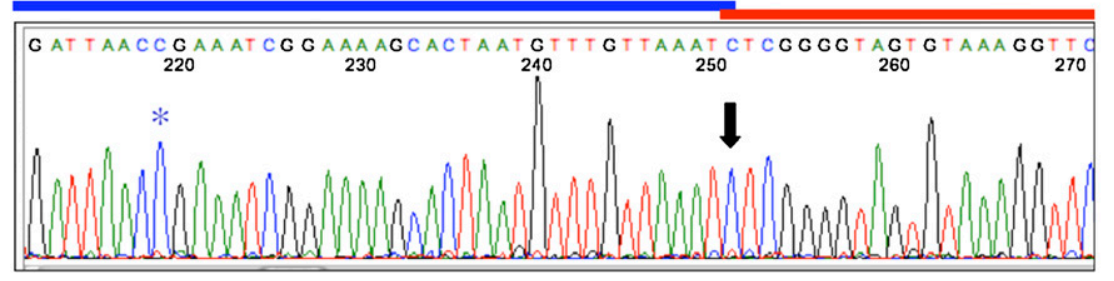

FIGURE 3. No extra $G$ is present at the ppoRNA-tRNA ${ }^{\text {met2 }}$ boundary in RNA precursors containing added nucleotides at other positions. Sequence traces of bulk PCR and RT-PCR products derived from mitochondrial DNA $(A)$ and nascent transcripts $(B)$ containing the $3^{\prime}$ end of the mitochondrial small subunit rRNA (SSU), ppoRNA, tRNA ${ }^{\text {met2 }}$, and tRNA ${ }^{\text {lys }}$. The region encoding the $3^{\prime}$ portion of ppoRNA (blue line) and the $5^{\prime}$ portion of tRNA ${ }^{\text {met } 2}$ (red line) is enlarged here. The traces from which these are extracted are shown in Supplemental Figure S1. The site of potential overlap of the ppoRNA and tRNA ${ }^{\text {met2 }}$ is indicated by a black arrow, and the nonencoded $\mathrm{C}$ inserted in this portion of the ppoRNA is marked with a blue asterisk. conclude that the $\mathrm{G}$ at the $5^{\prime}$ end of the mature tRNA ${ }^{\text {met2 }}$ is not derived from a $G$ inserted into the nascent transcript.

\section{Detection of a $\mathrm{G}$ addition activity in isolated}

A partially purified activity from A. castellanii (Price and Gray 1999a) and S. punctatus (Bullerwell and Gray 2005) mitochondria is capable of removing nucleotides from the $5^{\prime}$ end of tRNA substrates and replacing them in a $3^{\prime}$-to- $5^{\prime}$ direction using the $3^{\prime}$ portion of the acceptor stem as template. To investigate whether a similar activity might be present in Physarum mitochondria, we carried out labeling experiments with isolated organelles. These experiments were done in three different buffers: (1) our standard mitochondrial transcription buffer, (2) the buffer used to characterize the A. castellanii $5^{\prime}$ replacement activity, and (3) a modified version of the $A$. castellanii buffer containing a lower level of $\mathrm{Mg}^{+2}$ (see Materials and Methods). Mitochondria were isolated and preincubated in buffer to reduce endogenous nucleotide pools prior to the addition of $\left[\alpha-{ }^{32} \mathrm{P}\right]-$ UTP or $\left[\alpha-{ }^{32} \mathrm{P}\right]-$ GTP. After a 30-min incuba, nucleic acids were isolated and subjected to gel would be expected due to (1) the limited amount of transcription observed under severely limiting nucleotide concentrations (Visomirski-Robic and Gott 1997) and (2) the relatively short incubation times, which might not be sufficient for complete processing of the very large precursor. Indeed, only trace amounts of labeled nucleotides were incorporated into mature tRNA species when mitochondria were incubated in transcription buffer (Fig. 4, lanes 2,3). Strikingly, however, under conditions optimal for the A. castellanii tRNA replacement activity, significant incorporation of labeled nucleotide into endogenous tRNA was observed when $\left[\alpha^{32} \mathrm{P}\right]$-GTP (Fig. 4, lanes 4,6$)$ but not $\left[\alpha-{ }^{32} \mathrm{P}\right]$-UTP (Fig. 4 , lanes 5,7) was present. This result cannot be explained by differences in endogenous nucleotide pools, since GTP levels are significantly higher than UTP levels in isolated mitochondria (L VisomirskiRobic, unpubl.). These data indicate that there is an activity present in Physarum mitochondria that is capable of posttranscriptional addition of GTP into RNAs that comigrate with mature tRNAs (Fig. 4, lane 8). 


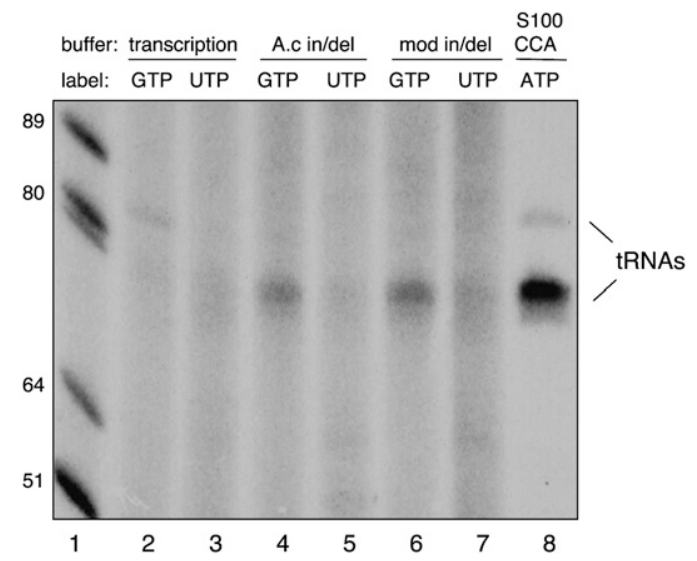

FIGURE 4. Processed tRNAs are preferentially labeled with $\left[\alpha^{32} \mathrm{P}\right] \mathrm{GTP}$ in isolated mitochondria. Isolated mitochondria were incubated in transcription buffer (lanes 2,3), the optimal buffer for the $A$. castellanii $5^{\prime}$ editing activity (lanes 4,5 ), or a modified version of the A. castellanii buffer (lanes 6,7), in the presence of $\left[\alpha-{ }^{32} \mathrm{P}\right] \mathrm{GTP}$ (lanes $2,4,6$ ) or $\left[\alpha-{ }^{32} \mathrm{P}\right] \mathrm{UTP}$ (lanes $3,5,7$ ) as described in Materials and Methods. Lane 8 shows the position of mature tRNAs labeled with $\left[\alpha-{ }^{32} \mathrm{P}\right]$ ATP by the CCA-adding activity present in S100 extracts derived from Physarum mitochondria. End-labeled, denatured DNA size markers are shown in lane 1 .

Thirteen of the 16 tRNAs encoded in the A. castellanii mitochondrial genome contain mismatches in their acceptor stems (Lonergan and Gray 1993a,b, Price and Gray 1999b). However, unlike the tRNAs studied here, the mismatches in A. castellanii tRNAs can occur anywhere within the proximal three positions of the acceptor stem, with some tRNAs containing two or even three mismatches (Lonergan and Gray 1993a). The A. castellanii tRNA editing activity is capable of deleting up to $3 \mathrm{nt}$ on the $5^{\prime}$ side of the acceptor stem and filling in the recessed end (Price and Gray 1999a). Interestingly, Physarum mitochondrial tRNAs were not labeled with UTP under replacement conditions (Fig. 4, lanes 5,7), despite the fact that tRNA ${ }^{\text {met1 }}$ has a $\mathrm{U}$ at position 3 and tRNA ${ }^{\text {met2 }}$ has a $U$ at position 2 that could potentially be replaced if a putative deletion/addition activity similar to the $A$. castellanii enzyme were present in $P$. polycephalum mitochondria. Given that the mismatches in the two Physarum tRNAs are at the beginning of the acceptor stem, it may be that the putative editing activity in Physarum mitochondria is only capable of deleting a single nucleotide from the $5^{\prime}$ end of tRNAs. Alternatively, basepairing may simply inhibit nucleolytic removal of additional nucleotides, resulting in a much less robust signal.

The work presented here demonstrates that tRNA ${ }^{\text {metl }}$ and $\mathrm{tRNA}^{\mathrm{met} 2}$ are edited at their $5^{\prime}$ ends by replacement of $\mathrm{U}$ or C, respectively, by $\mathrm{G}$. Although $\mathrm{G}$ insertion has been observed previously as part of internal GU or GC dinucleotide insertions, this is the first report of single $G$ additions in Physarum mitochondria. Three major findings support our conclusion that editing at the $5^{\prime}$ end of these tRNAs is likely to occur via a post-transcriptional mecha- nism that is distinct from previously identified forms of editing in this organism. First, the existence of potential editing intermediates in processed tRNAs containing $3^{\prime}$ CCA ends is consistent with a post-transcriptional mechanism, but not with cotranscriptional nucleotide insertion. Second, the absence of an added nucleotide at the $5^{\prime}$ end of tRNA $^{\text {met2 }}$ in a polycistronic precursor that contains inserted nucleotides both upstream and downstream argues against cotranscriptional G insertion. Third, Physarum mitochondria contain an activity that specifically incorporates GTP into the $5^{\prime}$ end of mature tRNAs. tRNA ${ }^{\text {metl }}$ is also subject to editing by internal nucleotide insertions (Fig. 2; Antes et al. 1998); thus, this tRNA requires two different forms of RNA editing for its maturation. To our knowledge this is the first example of a tRNA that is edited both coand post-transcriptionally. Although we cannot rule out the existence of an entirely novel editing activity, it seems more likely (based on the fact that the GTP incorporation occurs under conditions optimal for the $5^{\prime}$ editing activity in $A$. castellanii mitochondria) that the $5^{\prime}$ tRNA editing activity in $P$. polycephalum mitochondria is related to the enzymes present in A. castellanii and S. punctatus. CCA-adding enzymes are present even in organisms having tRNAs with encoded CCA ends (Deutscher 1990), and we suggest that RNA repair activities that act specifically at the $5^{\prime}$ ends of tRNAs may actually be quite widespread in nature.

\section{MATERIALS AND METHODS}

\section{RNA isolation and circularization reactions}

Mitochondria were isolated in buffered sucrose (BSS) as described previously (Visomirski-Robic and Gott 1995) and lysed in $20 \mathrm{mM}$ Tris-HCl (pH 7.7), $1 \mathrm{mM}$ EDTA, and 0.1\% SDS. Total mitochondrial nucleic acids were deproteinized via sequential extractions with phenol:chloroform:isoamyl alcohol (25:24:1 [v:v:v]) and chloroform:isoamyl alcohol (24:1 [v:v]), followed by ethanol precipitation. After treatment with DNase I (Roche), mitochondrial RNAs were again deproteinized and precipitated. Enrichment for salt-soluble RNAs (sRNA) and circularization reactions were carried out essentially according to the method as described by Price and Gray (1999b). Briefly, $60 \mu \mathrm{g}$ of total mitochondrial RNA were brought to $1.2 \mathrm{M} \mathrm{NaCl}$, incubated overnight at $4^{\circ} \mathrm{C}$, and centrifuged $10 \mathrm{~min}$ at $12,000 \mathrm{~g}$ at $4^{\circ} \mathrm{C}$. RNAs present in the supernatant were precipitated with ethanol, resuspended, deproteinized, and again precipitated with ethanol. Five micrograms of sRNA were heated for $5 \mathrm{~min}$ to $90^{\circ} \mathrm{C}$, quickly cooled on ice, and then incubated overnight at $37^{\circ} \mathrm{C}$ in $50 \mathrm{mM}$ HEPES ( $\mathrm{pH}$ 7.5), 15 $\mathrm{mM} \mathrm{MgCl} 2,3.3 \mathrm{mM}$ DTT, $10 \%$ DMSO, $0.01 \mu \mathrm{g} / \mu \mathrm{L}$ BSA, and 80 $\mu \mathrm{M}$ ATP with 10 units T4 RNA ligase (Promega). Ligated RNAs were deproteinized, precipitated with ethanol, and resuspended in $10 \mu \mathrm{L}$ of water.

\section{RT-PCR and PCR reactions}

For cDNA synthesis from circularized tRNAs, $1 \mu \mathrm{g}$ ligated sRNA was mixed with $1 \mathrm{pmol}$ of primer, heated for $2 \mathrm{~min}$ to $90^{\circ} \mathrm{C}$, cooled 
to room temperature over $\sim 20 \mathrm{~min}$, and incubated on ice for 15 min. Annealed primer templates were then incubated in $50 \mathrm{mM}$ Tris ( $\mathrm{pH} 8.3$, at $42^{\circ} \mathrm{C}$ ), $50 \mathrm{mM} \mathrm{KCl}, 10 \mathrm{mM} \mathrm{MgCl}_{2}, 10 \mathrm{mM} \mathrm{DTT}$, $0.5 \mathrm{mM}$ spermidine, and $60 \mu \mathrm{M}$ each dNTP with 10 units of AMV reverse transcriptase (Life Sciences) for $45 \mathrm{~min}$ at $42^{\circ} \mathrm{C}$. Primers used for cDNA synthesis were as follows: cirRTmet1.3 (5'-GAGG CACACGTTTTACC-3'), cirRTmet2.1 (5'-AGCCCTGTATGCGAA CC-3'), and cirRTprol (5'-AACCGAATGCTCTACCAG-3'). Onetenth of the appropriate cDNA was used as the template in subsequent PCR reactions using Taq polymerase (Roche) under conditions suggested by the supplier. Primers were phosphorylated by incubation with polynucleotide kinase prior to PCR reactions containing cirRTmet1.3 and cirmet1.4 (5' -TCGGTAGTTCGATTC TAC-3'), cirRTmet2.1 and cirmet2.2 (5'-TGGTTCGATTCCAGGC C-3'), or cirRTpro1 and cirpro2 (5'-GGGACCGAAAGGTTGC- $3^{\prime}$ ). The resulting RT-PCR products were gel purified and ligated to pBSM13+ (Stratagene) that had been digested with SmaI (New England Biolabs) and treated with calf intestine alkaline phosphatase (Roche).

For cDNA synthesis from nascent transcripts, $2 \mu \mathrm{g}$ of total mitochondrial RNA in $10 \mathrm{mM}$ Tris $\left(\mathrm{pH} 8.3\right.$, at $\left.42^{\circ} \mathrm{C}\right)$ and $250 \mathrm{mM} \mathrm{KCl}$ were mixed with primer cirRTprol, heated for $3 \mathrm{~min}$ to $95^{\circ} \mathrm{C}$, incubated for $10 \mathrm{~min}$ at $65^{\circ} \mathrm{C}$, and then held on ice. Reverse transcription was carried out in $25 \mathrm{mM}$ Tris $\left(\mathrm{pH} 8.3\right.$, at $\left.42^{\circ} \mathrm{C}\right), 125 \mathrm{mM}$ $\mathrm{KCl}, 15 \mathrm{mM} \mathrm{MgCl}_{2}, 7.5 \mathrm{mM}$ DTT, and $380 \mu \mathrm{M}$ each dNTP with 5 units of AMV reverse transcriptase (Life Sciences) for $1 \mathrm{~h}$ at $42^{\circ} \mathrm{C}$. One-tenth of the cDNA product was used in a PCR reaction using primers $1 s s u\left(5^{\prime}\right.$-TCACGTACAGACCGCCC-3') and tRNAK3 (5'TGGTTGGCTCCACAGGACTTGC- $3^{\prime}$ ) and Taq polymerase (New England BioLabs) under recommended conditions. A parallel reaction containing $100 \mathrm{ng}$ total mitochondrial nucleic acid was carried out to amplify the genomic sequence. The RT-PCR and PCR products were gel purified and sequenced directly by Biotic Solutions.

\section{Labeling experiments}

Mitochondria were isolated as described above and preincubated in the appropriate buffer (see below) for $5 \mathrm{~min}$ at $35^{\circ} \mathrm{C}$ prior to the addition of nucleotide. Mitochondria at a final concentration of $0.75 \mathrm{mg} / \mathrm{mL}$ were then incubated with $0.3 \mu \mathrm{M}\left[\alpha-{ }^{32} \mathrm{P}\right] \mathrm{UTP}$ or $\left[\alpha{ }^{32} \mathrm{P}\right]$ GTP for $30 \mathrm{~min}$ at $35^{\circ} \mathrm{C}$. Reactions were stopped by the addition of 4 volumes of stop mix (20 mM Tris- $\mathrm{HCl}$ [pH 7.5], 15 mM EDTA, 0.25\% SDS) followed by sequential extractions with phenol:chloroform:isoamyl alcohol (25:24:1) and chloroform: isoamyl alcohol (24:1). Nucleic acids were precipitated with ethanol, resuspended in $10 \mathrm{mM}$ Tris- $\mathrm{HCl}(\mathrm{pH} 7.5)$ and $1 \mathrm{mM}$ EDTA, and electrophoresed on an $8 \%$ denaturing acrylamide gel. The composition of the incubation buffers is as follows: Transcription buffer: $20 \mathrm{mM}$ Tris- $\mathrm{HCl}$ ( $\mathrm{pH} 7.5$ ), $20 \mathrm{mM} \mathrm{MgCl}_{2}, 10$ mM KCl, 2 mM DTT; A. castellanii deletion/insertion buffer: 40 mM HEPES (pH 7), $7.5 \mathrm{mM} \mathrm{MgCl}_{2}, 5 \mathrm{mM} \mathrm{KCl}, 1 \mathrm{mM}$ DTT; Modified A. castellanii buffer: $40 \mathrm{mM}$ HEPES ( $\mathrm{pH} 7), 5 \mathrm{mM}$ $\mathrm{MgCl}_{2}, 5 \mathrm{mM} \mathrm{KCl}, 1 \mathrm{mM}$ DTT.

The tRNA marker in Figure 4, lane 8, was generated by the endogenous CCA-adding activity. An S100 extract from Physarum mitochondria was preincubated in $15 \mathrm{mM}$ Tris- $\mathrm{HCl}$ ( $\mathrm{pH} 7.8$ ), 10 $\mathrm{mM} \mathrm{MgCl}, 5 \mathrm{mM} \mathrm{KCl}, 1.5 \mathrm{mM} \mathrm{DTT}$, and 5\% glycerol for $5 \mathrm{~min}$ at $35^{\circ} \mathrm{C}$ to deplete nucleotide pools and then incubated in the presence of $\left[\alpha-{ }^{32} \mathrm{P}\right] \mathrm{ATP}$ and CTP for an additional $30 \mathrm{~min}$ at $35^{\circ} \mathrm{C}$ prior to nucleic acid isolation and gel electrophoresis as described above.

\section{SUPPLEMENTAL MATERIAL}

Supplemental material can be found at http://www.rnajournal.org.

\section{ACKNOWLEDGMENTS}

We thank Neeta Parimi and Angela Stout for early contributions to this project, and Murray N. Schnare for generating the tRNA secondary structure diagrams. Funding for this work was provided by NIH grant GM54663 to J.M.G. and CIHR grant MOP-4124 to M.W.G.

Received October 9, 2009; accepted December 16, 2009.

\section{REFERENCES}

Alfonzo JD, Blanc V, Estévez AM, Rubio MA, Simpson L. 1999. C to $\mathrm{U}$ editing of the anticodon of imported mitochondrial tRNA ${ }^{\text {Trp }}$ allows decoding of the UGA stop codon in Leishmania tarentolae. EMBO J 18: 7056-7062.

Antes T, Costandy H, Mahendran R, Spottswood M, Miller D. 1998. Insertional editing of mitochondrial tRNAs of Physarum polycephalum and Didymium nigripes. Mol Cell Biol 18: 7521-7527.

Beargie C, Liu T, Corriveau M, Lee HY, Gott J, Bundschuh R. 2008. Genome annotation in the presence of insertional RNA editing. Bioinformatics 24: 2571-2578.

Binder S, Marchfelder A, Brennicke A. 1994. RNA editing of tRNA ${ }^{\text {Phe }}$ and $\mathrm{RRNA}^{\mathrm{Cys}}$ in mitochondria of Oenothera berteriana is initiated in precursor molecules. Mol Gen Genet 244: 67-74.

Bullerwell CE, Gray MW. 2005. In vitro characterization of a tRNA editing activity in the mitochondria of Spizellomyces punctatus, a chytridiomycete fungus. J Biol Chem 280: 2463-2470.

Byrne EM, Gott JM. 2004. Unexpectedly complex editing patterns at dinucleotide insertion sites in Physarum mitochondria. Mol Cell Biol 24: 7821-7828.

Cheng YW, Visomirski-Robic LM, Gott JM. 2001. Non-templated addition of nucleotides to the $3^{\prime}$ end of nascent RNA during RNA editing in Physarum. EMBO J 20: 1405-1414.

Cooley L, Appel B, Söll D. 1982. Post-transcriptional nucleotide addition is responsible for the formation of the $5^{\prime}$ terminus of histidine tRNA. Proc Natl Acad Sci 70: 6475-6479.

Deutscher MP. 1990. Ribonucleases, tRNA nucleotidyltransferase, and the 3' processing of tRNA. Prog Nucleic Acid Res Mol Biol 39: 209-240.

Gott JM, Rhee AC. 2007. Insertion/deletion editing in Physarum polycephalum. In RNA editing (ed. HU Goringer), pp. 85-104. Springer-Verlag, Berlin.

Gott JM, Visomirski LM, Hunter JL. 1993. Substitutional and insertional RNA editing of the cytochrome $c$ oxidase subunit 1 mRNA of Physarum polycephalum. J Biol Chem 268: 25483-25486.

Gott JM, Parimi N, Bundschuh R. 2005. Discovery of new genes and deletion editing in Physarum mitochondria enabled by a novel algorithm for finding edited mRNAs. Nucleic Acids Res 33: 5063-5072.

Janke A, Pääbo S. 1993. Editing of a tRNA anticodon in marsupial mitochondria changes its codon recognition. Nucleic Acids Res 21: 1523-1525.

Jühling F, Mörl M, Hartmann RK, Sprinzl M, Stadler PF, Pütz J. 2009. tRNAdb 2009: Compilation of tRNA sequences and tRNA genes. Nucleic Acids Res 37: D159-D162.

Laforest M-J, Roewer I, Lang BF. 1997. Mitochondrial tRNAs in the lower fungus Spizellomyces punctatus: tRNA editing and UAG "stop" codons recognized as leucine. Nucleic Acids Res 25: 626632. 


\section{Gott et al.}

Leigh J, Lang BF. 2004. Mitochondrial 3' tRNA editing in the jakobid Seculamonas ecuadoriensis: A novel mechanism and implications for tRNA processing. RNA 10: 615-621.

Lohan AJ, Gray MW. 2004. Methods for analysis of tRNA editing in Acanthamoeba castellanii. Methods Mol Biol 265: 315-332.

Lohan AJ, Gray MW. 2007. Analysis of $5^{\prime}$ - or $3^{\prime}$-terminal tRNA editing: Mitochondrial 5' tRNA editing in Acanthamoeba castellanii as the exemplar. Methods Enzymol 424: 221-242.

Lonergan KM, Gray MW. 1993a. Editing of transfer RNAs in Acanthamoeba castellanii mitochondria. Science 259: 812-816.

Lonergan KM, Gray MW. 1993b. Predicted editing of additional transfer RNAs in Acanthamoeba castellanii mitochondria. Nucleic Acids Res 21: 4402.

Mahendran R, Spottswood MR, Miller DL. 1991. RNA editing by cytidine insertion in mitochondria of Physarum polycephalum. Nature 349: 434-438.

Maréchal-Drouard L, Ramamonjisoa D, Cossett A, Weil JH, Dietrich A. 1993. Editing corrects mispairing in the acceptor stem of bean and potato mitochondrial phenylalanine transfer RNAs. Nucleic Acids Res 21: 4909-4914.

Maréchal-Drouard L, Kumar R, Remacle C, Small I. 1996a. RNA editing of larch mitochondrial tRNA ${ }^{\mathrm{His}}$ precursors is a prerequisite for processing. Nucleic Acids Res 24: 3229-3234.

Maréchal-Drouard L, Cosset A, Remacle C, Ramamonjisoa D, Dietrich A. 1996b. A single editing event is a prerequisite for efficient processing of potato mitochondrial phenylalanine tRNA. Mol Cell Biol 16: 3504-3510.

Miller D, Mahendran R, Spottswood M, Costandy H, Wang S, Ling ML, Yang N. 1993. Insertional editing in mitochondria of Physarum. Semin Cell Biol 4: 261-266.
Price DH, Gray MW. 1998. Editing of transfer RNA. In Modification and editing of RNA: The alteration of RNA structure and function (ed. H Grosjean and R Benne), pp. 289-305. ASM Press, Washington, DC.

Price DH, Gray MW. 1999a. A novel nucleotide incorporation activity implicated in the editing of mitochondrial transfer RNAs in Acanthamoeba castellanii. RNA 5: 302-317.

Price DH, Gray MW. 1999b. Confirmation of predicted edits and demonstration of unpredicted edits in Acanthamoeba castellanii mitochondrial tRNAs. Curr Genet 35: 23-29.

Takano H, Abe T, Sakurai R, Moriyama Y, Miyazawa Y, Nozaki H, Kawano S, Sasaki N, Kuroiwa T. 2001. The complete DNA sequence of the mitochondrial genome of Physarum polycephalum. Mol Gen Genet 264: 539-545.

Tomita K, Ueda T, Watanabe K. 1996. RNA editing in the acceptor stem of squid mitochondrial tRNA ${ }^{\mathrm{Tyr}}$. Nucleic Acids Res 24: 49874991.

Visomirski-Robic LM, Gott JM. 1995. Accurate and efficient insertional RNA editing in isolated Physarum mitochondria. RNA 1: $681-691$.

Visomirski-Robic LM, Gott JM. 1997. Insertional editing in isolated Physarum mitochondria is linked to RNA synthesis. RNA 3: 821837.

Yokobori S-I, Pääbo S. 1995a. Transfer RNA editing in land snail mitochondria. Proc Natl Acad Sci 92: 10432-10435.

Yokobori S-I, Pääbo S. 1995b. tRNA editing in metazoans. Nature 377: 490.

Yokobori S, Pääbo S. 1997. Polyadenylation creates the discriminator nucleotide of chicken mitochondrial tRNA ${ }^{\mathrm{Tyr}}$. J Mol Biol 265: 95-99. 

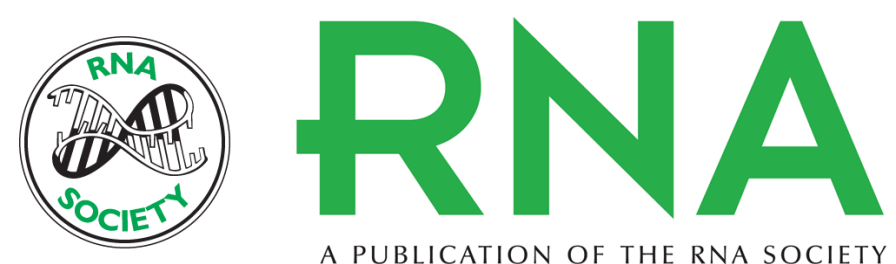

A PUBLICATION OF THE RNA SOCIETY

\section{Two forms of RNA editing are required for tRNA maturation in Physarum mitochondria}

Jonatha M. Gott, Benjamin H. Somerlot and Michael W. Gray

RNA 2010 16: 482-488 originally published online January 27, 2010

Access the most recent version at doi:10.1261/rna.1958810

\section{Supplemental http://rnajournal.cshlp.org/content/suppl/2010/01/28/rna.1958810.DC1 \\ Material}

References This article cites 33 articles, 12 of which can be accessed free at:

http://rnajournal.cshlp.org/content/16/3/482.full.html\#ref-list-1

\section{License}

Email Alerting Receive free email alerts when new articles cite this article - sign up in the box at the Service top right corner of the article or click here.

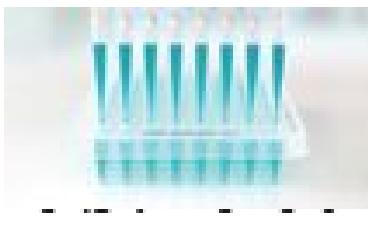

Providing Precise Solutions for your research.

To subscribe to $R N A$ go to:

http://rnajournal.cshlp.org/subscriptions 